\title{
Photoluminescent Properties of Hydroxyapatite and Hydroxyapatite/Multi-Walled Carbon Nanotube Composites
}

\author{
Edna X. Figueroa-Rosales ${ }^{1}{ }^{\mathbb{D}}$, Javier Martínez-Juárez ${ }^{2}$, Esmeralda García-Díaz ${ }^{3} \mathbb{D}$, Daniel Hernández-Cruz ${ }^{4}$, \\ Sergio A. Sabinas-Hernández ${ }^{5}$ ad and Maria J. Robles-Águila ${ }^{2, * \mathbb{C}}$
}

1 Instituto de Ciencias, Posgrado en Dispositivos Semiconductores, Benemérita Universidad Autónoma de Puebla, Av. San Claudio y Boulevard 14 Sur, Ciudad Universitaria, Puebla 72570, Mexico; edna.figueroa@viep.com.mx

2 Instituto de Ciencias, Centro de Investigación en Dispositivos Semiconductores, Benemérita Universidad Autónoma de Puebla, Av. San Claudio y Boulevard 14 Sur, Ciudad Universitaria, Puebla 72570, Mexico; javier.martinez@viep.com.mx

3 Instituto de Ciencias, Centro de Química, Benemérita Universidad Autónoma de Puebla, Ciudad Universitaria, Puebla 72570, Mexico; esmeralda.garcia@correo.buap.mx

4 Facultad de Ingeniería, Universidad Autónoma de Chiapas, Blvd. Belisario Domínguez, Km. 108, Tuxtla Gutiérrez, Chiapas 29050, Mexico; daniel.hernandez@unach.mx

5 Instituto de Física, Benemérita Universidad Autónoma de Puebla, Av. San Claudio y Blvd. 18 Sur, Col. San Manuel, Ciudad Universitaria, Apartado postal J-48, Puebla 72570, Mexico; ssabinas@ifuap.buap.mx

check for updates

Citation: Figueroa-Rosales, E.X.; Martínez-Juárez, J.; García-Díaz, E.; Hernández-Cruz, D.;

Sabinas-Hernández, S.A.; Robles-Águila, M.J.

Photoluminescent Properties of

Hydroxyapatite and

Hydroxyapatite/Multi-Walled

Carbon Nanotube Composites. Crystals 2021, 11, 832. https:// doi.org/10.3390/cryst11070832

Academic Editors: Réka Barabás,

Liliana Bizo and

Graziella-Liana Turdean

Received: 25 June 2021

Accepted: 14 July 2021

Published: 17 July 2021

Publisher's Note: MDPI stays neutral with regard to jurisdictional claims in published maps and institutional affiliations.

Copyright: (c) 2021 by the authors. Licensee MDPI, Basel, Switzerland. This article is an open access article distributed under the terms and conditions of the Creative Commons Attribution (CC BY) license (https:// creativecommons.org/licenses/by/ $4.0 /)$.
* Correspondence: josefina.robles@correo.buap.mx; Tel.: +52-(222)-229-5500 (ext. 7869)

\begin{abstract}
Hydroxyapatite (HAp) and hydroxyapatite/multi-walled carbon nanotube (MWCNT) composites were obtained by the co-precipitation method, followed by ultrasound-assisted and microwave radiation and thermal treatment at $250{ }^{\circ} \mathrm{C}$. X-ray diffraction (XRD) confirmed the presence of a hexagonal phase in all the samples, while Fourier-transform infrared (FTIR) spectroscopy elucidated the interaction between HAp and MWCNTs. The photoluminescent technique revealed that HAp and the composite with non-functionalized MWCNTs present a blue luminescence, while the composite with functionalized MWCNTs, under UV-vis radiation shows an intense white emission. These findings allowed presentation of a proposal for the use of HAp and HAp with functionalized MWCNTs as potential materials for optoelectronic and medical applications.
\end{abstract}

Keywords: hydroxyapatite; multi-walled carbon nanotubes; composites; photoluminescence

\section{Introduction}

Hydroxyapatite $\left[\mathrm{Ca}_{10}\left(\mathrm{PO}_{4}\right)_{6}(\mathrm{OH})_{2}\right]$ is a bioceramic material used in medical applications [1] and widely studied due to its compatibility with the hydroxyapatite (HAp) present in human bones and other tissues of the body [2]. Furthermore, hydroxyapatite is naturally found in vertebrate hard tissues [3] and invertebrate shells [4]. Currently, hydroxyapatite is used for other purposes, e.g., as a heterogeneous catalyst [5], an adsorbent [6], a source of biofuel cells [7], a bioimaging agent [8], in glassy carbon electrodes [9], and in drug-delivery carriers [10].

Recently, bioimaging agents from HAp have been reported to monitor certain changes in the human body owing to its characteristic excitation and emission profiles. To improve its photoluminescent properties, hydroxyapatite has been synthesized with a number of ions partially replacing $\mathrm{Ca}^{2+}$, in this case of transition metals such as $\mathrm{Fe}^{3+}$ [11] and $\mathrm{Mn}^{2+}[12]$, or rare earth elements such as $\mathrm{Tb}^{3+}, \mathrm{La}^{3+}, \mathrm{Er}^{3+}, \mathrm{Dy}^{3+}, \mathrm{Eu}^{3+}$, and $\mathrm{Gd}^{3+}[13,14]$. Several research studies have reported that the intensity of photoluminescence emissions from rare earth elements is strongly related to the surrounding ions and their concentration because they deliver the chemical environmental information and vibrating coupling among $f$ - $d$ or $f-f$ electronic transitions [15]. However, these goals are not always achieved, and, as an example, there is the work of Chen et al., who observed quenching effects 
when doping HAp with the $\mathrm{Fe}^{3+}$ ion [11]. Moreover, transition metals are toxic and have an aggregation-caused quenching (ACQ) effect on conventional fluorophores, thus excluding their practical application $[16,17]$. Therefore, the use of non-toxic materials and the elimination of the ACQ effect are required characteristics to favor the emission of light.

Despite these inconveniences, extensive research on carbon nanotubes (CNTs) used in a variety of applications has been reported due to their excellent biocompatibility, large surface area, and structural, optical, thermal, electrical, and mechanical properties [18-20]. CNTs are classified as single-walled carbon nanotubes (SWCNTs), double-walled carbon nanotubes (DWCNTs), and multi-walled carbon nanotubes (MWCNTs) [21,22]. Riggs et al. have reported luminescent properties of SWCNTs and MWCNTs dispersed in polymers, whereas O'Connell et al. have observed fluorescent properties in SWCNTs [23,24].

Several reports have focused on preparing composites from CNTs and other materials as metal oxides ( $\mathrm{ZnO}, \mathrm{Fe}_{2} \mathrm{O}_{3}, \mathrm{TiO}_{2}$,), graphene, and bioceramic materials, such as $\mathrm{HAp}$, to generate a synergistic effect $[25,26]$. The incorporation of MWCNTs into HAp, influences structural, optical, and mechanical properties that enhance biocompatibility, adhesiveness, and corrosion resistance [27]. Ma et al. reported the fluorescence of HAp with carbon quantum dots for biological applications [28]. In a different study, the cell imagining capacity was commonly evaluated at 405 and $488 \mathrm{~nm}$ by focal laser scanning microscopy. Emissions in the UV-visible range can transfer luminescence resonance energy to drugs that absorb in the visible range for real-time drug release monitoring [8]. Currently, research on imaging agents using carbon and HAp has been reported, but research in this area using CNTs has been extremely limited until now.

Different methods have been used to prepare composites from HAp and MWCNTs, such as chemical precipitation, chemical vapor deposition, ball milling, ultrasonication, spark plasma sintering, electrodeposition, sol-gel, and co-precipitation methods [19,20,29-31]. In this paper, HAp and HAp/MWCNT composites were synthesized by the co-precipitation method, followed by ultrasound-assisted and microwave radiation, using functionalized and non-functionalized MWCNTs with potential optoelectronic and medical applications.

\section{Experimental Methods}

\subsection{Hydroxyapatite Synthesis}

Calcium nitrate $\left(\mathrm{Ca}\left(\mathrm{NO}_{3}\right)_{2} \bullet 4 \mathrm{H}_{2} \mathrm{O}, 100 \%\right.$ Fermont), di-ammonium hydrogen phosphate ( $\left[\mathrm{NH}_{4}\right]_{2} \mathrm{HPO}_{4}, 99.3 \%$ Fermont), $\mathrm{C}_{4} \mathrm{H}_{11} \mathrm{NO}_{3}$ Trizma base $\left(\mathrm{C}_{4} \mathrm{H}_{11} \mathrm{NO}_{3}, \geq 99.9 \%\right.$ SigmaAldrich, St. Louis, MO, USA), and ammonium hydroxide $\left(\mathrm{NH}_{4} \mathrm{OH}, 28-30 \%\right.$ Meyer, Mexico City, Mexico) were used as HAp precursors. Hexadecyltrimethylammonium (CTAB, 99\% Sigma Aldrich, St. Louis, MO, USA) was used as a surfactant agent.

A solution of $0.1 \mathrm{M}$ Trizma base ( $\mathrm{pH}$ buffer) was used to prepare the di-ammonium hydrogen phosphate and calcium nitrate solutions. A solution of $0.4 \mathrm{M}$ di-ammonium hydrogen phosphate $\left(\left[\mathrm{NH}_{4}\right]_{2} \mathrm{HPO}_{4}\right.$ in $50 \mathrm{~mL}$ of $0.1 \mathrm{M}$ Trizma solution) was stirred at room temperature, and then a solution of $0.85 \mathrm{M}$ of calcium nitrate $\left(\mathrm{Ca}\left(\mathrm{NO}_{3}\right)_{2} \bullet 4 \mathrm{H}_{2} \mathrm{O}\right.$ in $50 \mathrm{~mL}$ of $0.1 \mathrm{M}$ Trizma solution) was slowly poured dropwise into the phosphate solution. A solution of $0.1 \mathrm{M} \mathrm{CTAB} \mathrm{(} 25 \mathrm{ml}$ of a 4:1 $v / v$ water-ethanol mixture) was added with constant stirring. The $\mathrm{pH}$ solution was adjusted with ammonium hydroxide $\left(\mathrm{NH}_{4} \mathrm{OH}\right)$ at values from 9 to 11. After $24 \mathrm{~h}$, the mixture was ultrasonicated in a Cole-Parmer model 08895-04 ultrasonic bath for $2 \mathrm{~h}$. Additionally, $1200 \mathrm{~W}$ microwave radiation was applied to the mixture for $10 \mathrm{~min}$ (Sharp model Carousel), which was then maintained with stirring for $24 \mathrm{~h}$. The material was thoroughly washed with a distilled water/ethanol (1:1) mixture to eliminate the residual salts left from synthesis and dried at $100{ }^{\circ} \mathrm{C}$ for $2 \mathrm{~h}$ and $30 \mathrm{~min}$ in a Sev model MF3 muffle. Finally, the sample was ground in an agate mortar and then subjected to a heat treatment at $250{ }^{\circ} \mathrm{C}$ for $6 \mathrm{~h}$ (Sev model MF3) to obtain the HAp powder. 


\subsection{Composite Preparation}

Two different types of MWCNTs were used in the composite samples. MWCNTs with oxygen-containing functional groups (OMWCNTs, carboxyl groups), were synthesized by using the Castle methodology [32], and MWCNTs were purchased from Timesnano. In each sample, $25 \mathrm{mg}$ of nanotubes were dispersed in $2.5 \%$ of Triton X100 solution to prevent agglomeration. Dispersed nanotubes were added to the HAp precursor as shown in Figure 1, practically following the HAp preparation route to obtain the HAp/OMWCNT and HAp/MWCNT composites.

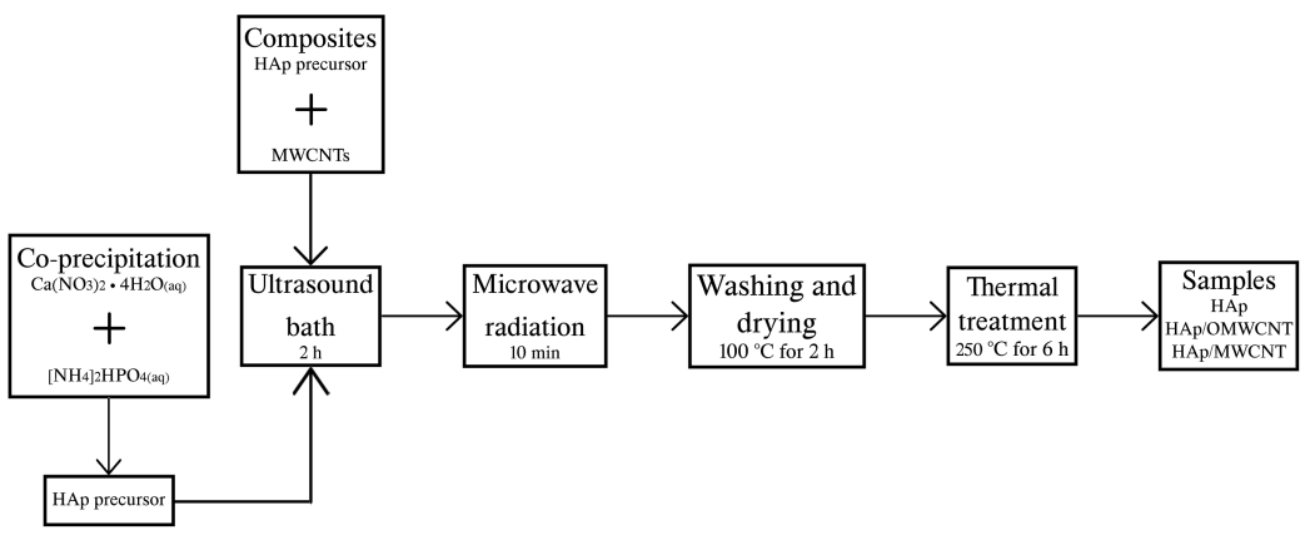

Figure 1. Diagram of the synthesis of HAp and HAp/OMWCNT and HAp/MWCNT composites.

\subsection{Characterization}

X-ray powder diffraction (XRD) patterns were collected at the Elettra Synchrotron Trieste (Trieste, Italy), on XRD1 beamline, with these settings: in the $2 \theta$ range from 0 to $50^{\circ}$ at $\lambda=1 \AA$. The samples were placed in a borosilicate glass capillary at a $360^{\circ}$ rotation and exposed for $30 \mathrm{~s}$. The standard reference used was NIST lanthanum hexaboride $\left(\mathrm{LaB}_{6}\right)$. Diffraction images were obtained and integrated using the Fit2d program to extract the patterns as a function of $2 \theta$. The PDF-4+2019 database from ICDD was used to identify the phases in each sample [33]. Refinement analyses were performed using the BGMN/Autoquan software version 4.2.22 [34] with the graphical user interface Profex version 4.3.2 [35]. The background profile was fitted combining a Lagrange polynomial and an empty capillary scan measured under the same sample conditions. Crystallographic information of the hexagonal HAp phase was taken from ICSD-PDF-2: 01-074-0565, and it was fixed in all refinements. Anisotropic crystallite size and isotropic microstrains were considered for line broadening. Additionally, texture in all samples was considered by scale factor. FTIR spectroscopy measurements were performed on a NicoletTM iSTM 10 FTIR spectrophotometer (Thermo Fisher Scientific, Waltham, MA, USA) from 4000 to $650 \mathrm{~cm}^{-1}$. The morphology was determined using the FEI-ESEM-Quanta 200 scanning electron microscope (SEM) (FEI, Hillsboro, OR, USA). Photoluminescent (PL) experiments were conducted on a NanoLog spectrofluorometer (Horiba NanoLog model FL-1057, Tokyo, Japan), and the materials were excited with a He-Cd laser at $325 \mathrm{~nm}$ and analyzed from 350 to $850 \mathrm{~nm}$. Compositional analysis was obtained by the energy dispersive spectroscopy (EDS) technique, using a Jeol JSM-6610LV scanning electron microscope (SEM) with a $\mathrm{Cu} \mathrm{K} \alpha(20 \mathrm{kV})$ excitation source (JEOL, Ltd., Tokyo, Japan), and by X-ray fluorescence spectroscopy (XRF), using beamline IDEAS from Canadian Light Source Inc. (Saskatoon, $\mathrm{SK}$, Canada) in the reading range from $\sim 2 \mathrm{KeV}$ to $13.5 \mathrm{KeV}$.

\section{Results and Discussion}

\subsection{X-ray Diffraction}

The XRD powder patterns of the HAp, HAp/OMWCNT, and HAp/MWCNT samples are shown in Figure $2 b-d$. The most intense Bragg peaks were identified by the 01074-0565 card from the PDF-2 database [36], unambiguously confirming, as expected, a 
hexagonal HAp phase and excluding the less common monoclinic HAp [37]. Figure 2a,e also present the reflections associated with MWCNTs and OMWCNTs (002), (100), and (004). The results indicated that the intensity of OMWCNTs decreased because their surface area was modified by functionalization, as reported in [27]. However, MWCNT reflections were not observed in the composite samples because they overlapped with HAp reflections. Nevertheless, differences in crystallinity between HAp and composites were observed in the peak intensity and definition in both powder patterns. During synthesis, the carbon nanotubes acted as nucleation centers for HAp, which allowed crystallites to grow on the MWCNT surface, depending on the type of carbon nanotubes contained in the samples [38]. The crystallite size of the samples was estimated by Rietveld analysis (see Table 1). Anisotropic crystallite size was obtained as expected due to the hexagonal lattice. Hydroxyapatite crystallite sizes along the $\langle 100\rangle$ crystallographic direction of HAp and HAp/MWCNT were almost equal to $10 \mathrm{~nm}$. Crystallite sizes along the $\langle 001\rangle$ crystallographic direction of HAp were slightly greater that those of the HAp/MWCNT composite, which indicated that the crystallite sizes in both samples were almost the same. The pattern intensity in the HAp/MWCNT sample was $~ 50 \%$ greater than that of the HAp. The HAp/OMWCNT crystallite sizes were $15.74 \mathrm{~nm}$ along $\langle 100\rangle$ and $30.9 \mathrm{~nm}$ along $\langle 001\rangle$ crystallographic directions, respectively, which were greater than those obtained in the HAp and HAp/MWCNT samples. Peak intensity in the HAp/OMWCNT sample was $\sim 70 \%$ greater than that in the HAp, which is shown in Figure $2 \mathrm{~d}$. Adding the MWCNT sample did not change the crystallite size of the HAp; however, adding the OMWCNT sample did increase it. This suggests that the OMWCNTs interact differently from the non-functionalized MWCNTs with the precursors of HAp under experimental conditions. Adding non-functionalized SWCNTs resulted in an increased crystallite size in the same way as the HAp [20], whereas in the work by Arul et al., the incorporation of functionalized MWCNTs caused a smaller crystallite size than that of the HAp [27]. The differences may be attributed to the working temperature during synthesis, because the experiments were carried out at room temperature in this work, whereas temperatures of 50 and $90^{\circ} \mathrm{C}$, respectively, were used in the reports cited above.

The Rietveld refinement did not indicate significant variations in the cell parameters $a$ and $c$ or in the cell volume. However, the HAp sample showed the greatest cell volume, and the HAp/OMWCNT composite has the greatest HAp crystallite size, while the microstrain had the smallest size, as expected according to this sample's crystallinity. Table 1 shows the fitting parameters determined through a comparison between the experimental and calculated diffraction patterns.

Figure 3 shows the Rietveld difference plot, where the fluctuation indicates a reasonable fitting between the observed and calculated diffraction patterns. The lower band shows the fitting deviation of original diffractograms.

Table 1. Results of the Rietveld analysis of HAp, HAp/MWCNT, and HAp/OMWCNT samples. The numbers in parentheses denote the uncertainty in the last digit.

\begin{tabular}{|c|c|c|c|c|c|c|c|c|}
\hline \multirow[t]{2}{*}{ Sample } & \multicolumn{2}{|c|}{ Cell Parameters } & \multirow{2}{*}{$\begin{array}{l}\text { Unit Cell Volume } \\
\text { (nm3) }\end{array}$} & \multicolumn{2}{|c|}{$\begin{array}{c}\text { Crystallite Sizes } \\
\text { (nm) }\end{array}$} & \multirow{2}{*}{$\begin{array}{l}\text { R. M. S. Strain } \\
\sqrt{\varepsilon_{i s o}^{2}} \times 100 \%\end{array}$} & \multirow[t]{2}{*}{ Rwp } & \multirow{2}{*}{$\begin{array}{c}\text { GoF } \\
\text { (Rwp/Rexp) }\end{array}$} \\
\hline & a (nm) & $c(n m)$ & & $\langle 100\rangle$ & $\langle 001\rangle$ & & & \\
\hline HAp & $0.94373(4)$ & 0.69093(3) & $0.61536(7)$ & $10.17(3)$ & $27.7(3)$ & $0.310(7)$ & 1.85 & 2.72 \\
\hline HAp/MWCNT & $0.94331(4)$ & $0.69095(3)$ & $0.61483(7)$ & $10.68(4)$ & 25.1(3) & $0.362(7)$ & 2.36 & 3.81 \\
\hline HAp/OMWCNT & $0.94367(2)$ & $0.69051(2)$ & $0.61491(5)$ & $15.74(5)$ & $30.9(3)$ & $0.186(6)$ & 2.56 & 4.00 \\
\hline
\end{tabular}




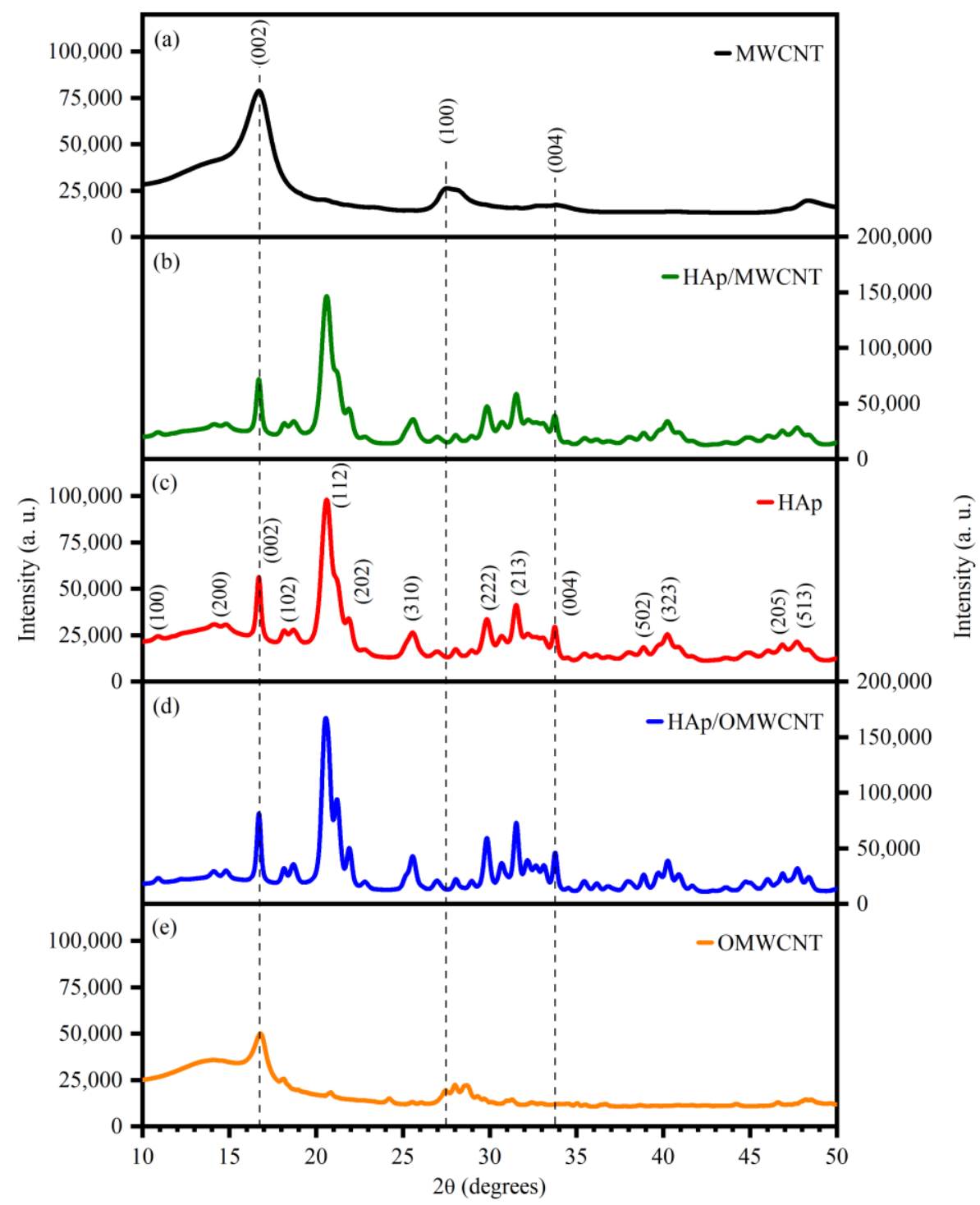

Figure 2. Diffraction patterns of the MWCNT (a), HAp/MWCNT (b), HAp (c), HAp/OMWCNT (d), and OMWCNT (e) samples. Vertical dashed lines indicate reflections associated with MWCNTs.
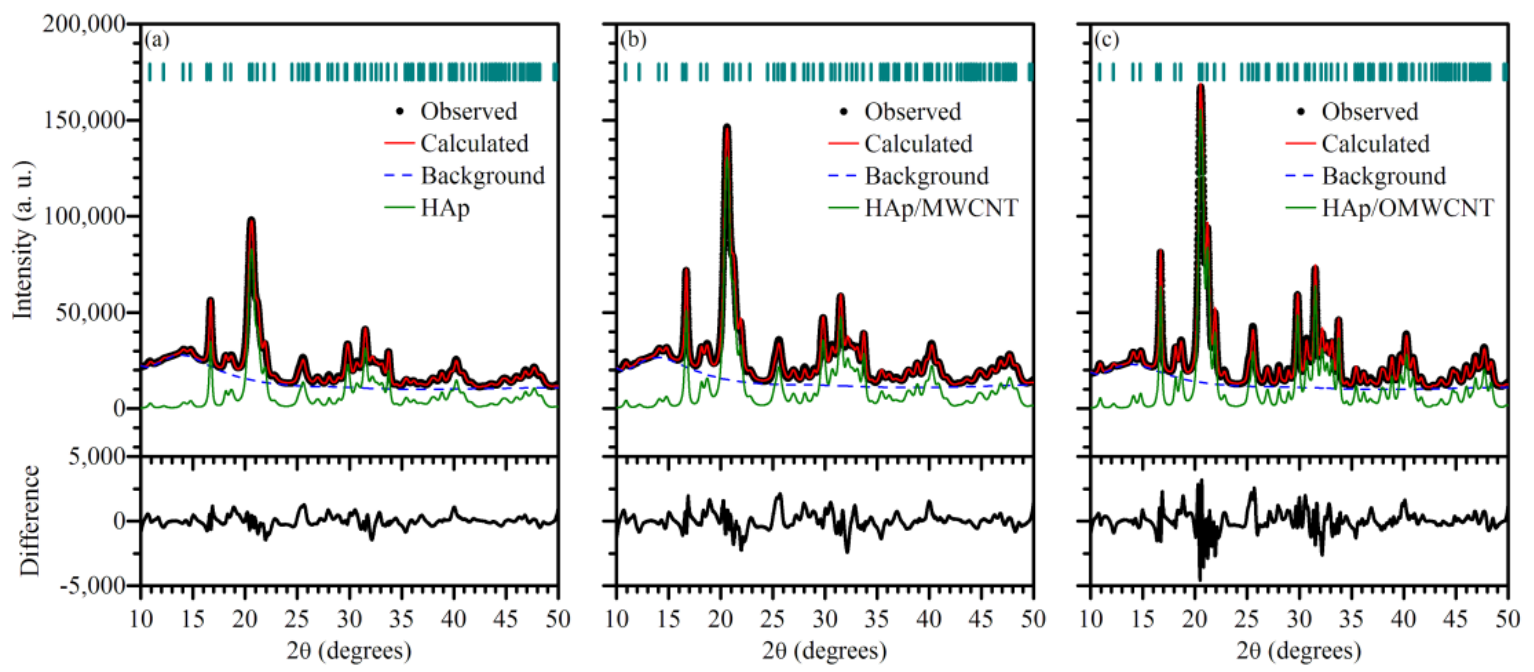

Figure 3. Rietveld refinement plot of HAp (a), HAp/MWCNT (b), HAp/OMWCNT (c). 


\subsection{FTIR Spectroscopy}

Figure 4 illustrates the characteristic vibrational modes of HAp identified and shown in the IR spectrum of each sample. Table 2 enlists the specific vibrational modes detected in each sample. The weak band at $3572 \mathrm{~cm}^{-1}$ was assigned to the $\mathrm{OH}^{-}$group. The vibrational modes related to $\mathrm{PO}_{4}{ }^{3-}$ ions were found at approximately $1000 \mathrm{~cm}^{-1}$, and their resonances were identified at the 1950-2200 $\mathrm{cm}^{-1}$ interval [39]. As shown in the inset in Figure 4, the band at $1630 \mathrm{~cm}^{-1}$ refers to adsorbed water [39,40], which appeared in both HAp and the HAp/OMWCNT samples. The band at $1325 \mathrm{~cm}^{-1}$ that appeared in the HAp/OMWCNT sample is associated with the interaction between the $\mathrm{Ca}^{2+}$ ion and the $\mathrm{COO}^{-}$group on the OMWCNT sample. According to [38], this band confirms the interaction between HAp and MWCNTs, which was corroborated by the XRD results. In addition, the band deconvolution approximately at $875 \mathrm{~cm}^{-1}$ showed a substitution of the $\mathrm{OH}^{-}\left(870 \mathrm{~cm}^{-1}\right.$ substitution type $\mathrm{A})$ and $\mathrm{PO}_{4}{ }^{3-}\left(877 \mathrm{~cm}^{-1}\right.$ substitution type $\left.\mathrm{B}\right)$ ions for the $\mathrm{CO}_{3}{ }^{2-}$ ion. The contribution of these substitutions was observed at the 1410-1540 $\mathrm{cm}^{-1}$ interval $[39,41]$. Bands attributed to the substitution in HAp had 17.74 and 17.04 a.u. for substitution types A and B, respectively. Band areas decreased significantly in the composites. The HAp/MWCNT sample had 9.35 and 12.30 a.u., respectively, while the HAp/OMWCNT sample had 7.37 and 12.45 a.u., respectively.

Figure 5 displays the probable interaction between HAp and OMWCNT. The FTIR results suggested that the $\mathrm{Ca}^{2+}$ ion from HAp is linked to the carboxylic groups from OMWCNT. Therefore, the nucleation centers promote the HAp growth on the surface of OWCNT. The HAp was modeled using VESTA software considering 100 atoms, while the OMWCNT was modeled with a Nanotube Modeler JCrystalSoft 1.8.0, and Spartan 1.1.4 using 676 atoms. The interaction of HAp and MWCNT could be explained by Van der Waals forces; however, theoretical studies are required to determine the bond energies.

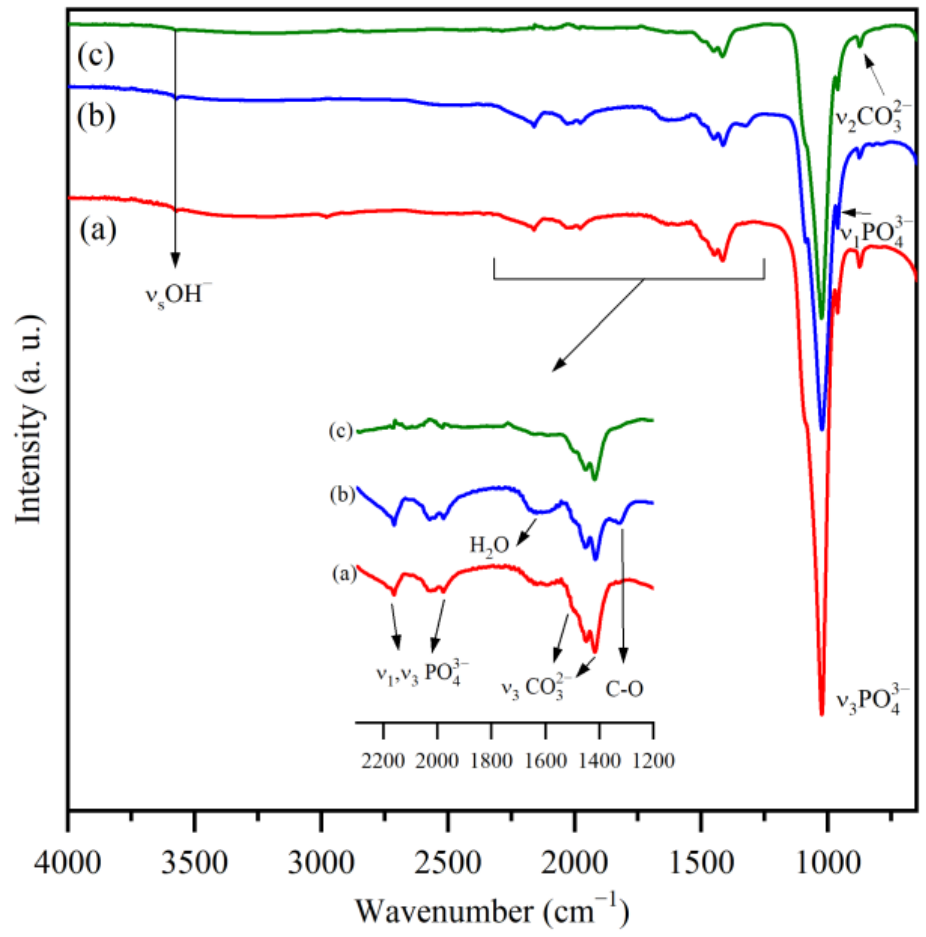

Figure 4. FTIR spectrum of the HAp (a), HAp/OMWCNT (b), and HAp/MWCNT (c) samples. 
Table 2. Position and assignment of the vibrational modes of the HAp and composite samples.

\begin{tabular}{|c|c|c|c|c|}
\hline \multicolumn{3}{|c|}{ Band Position ( $\left.\mathrm{cm}^{-1}\right)$} & \multirow{2}{*}{ Assignment } & \multirow{2}{*}{ Ref. } \\
\hline HAp & HAp/OMWCNT & HAp/MWCNT & & \\
\hline 3572 & 3572 & 3572 & $\mathrm{O}-\mathrm{H}$ stretching mode & {$[39,40]$} \\
\hline 1978-2187 & 1978-2184 & 1980-2188 & $\begin{array}{l}\text { Overtones and combinations of } v_{3} \mathrm{PO}_{4}{ }^{3-} \\
\text { and } v_{1} \mathrm{PO}_{4}{ }^{3-} \text { modes }\end{array}$ & {$[39,40]$} \\
\hline 1631 & 1631 & 1590 & Adsorbed water & {$[39,40]$} \\
\hline 875 & 875 & 875 & $\begin{array}{l}\mathrm{HPO}_{4} \text { mode and substitution types A and } \\
\text { B }\end{array}$ & {$[39,41]$} \\
\hline $1462-1512$ & $1461-1512$ & $1462-1495$ & $\mathrm{CO}_{3}^{2-}$ replacing $\mathrm{OH}^{-}$ & {$[39,41]$} \\
\hline 1448 & 1452 & 1451 & $\mathrm{CO}_{3}{ }^{2-}$ replacing $\mathrm{PO}_{4}^{3-}$ & {$[39,41]$} \\
\hline 1416 & 1415 & 1418 & $\mathrm{CO}_{3}{ }^{2-}$ replacing $\mathrm{PO}_{4}^{3-}$ & {$[39,41]$} \\
\hline- & 1326 & - & stretching mode of $-\mathrm{COOH}$ & [38] \\
\hline 1092 & 1088 & 1092 & $v_{3} \mathrm{PO}_{4}{ }^{3-}$ mode & {$[39,40]$} \\
\hline 1025 & 1024 & 1026 & $v_{3} \mathrm{PO}_{4}{ }^{3-}$ mode & {$[39,40]$} \\
\hline 962 & 962 & 962 & $v_{1} \mathrm{PO}_{4}^{3-}$ mode & {$[39,40]$} \\
\hline 876 & 877 & 875 & $\mathrm{CO}_{3}{ }^{2-}$ mode & {$[39,41]$} \\
\hline
\end{tabular}
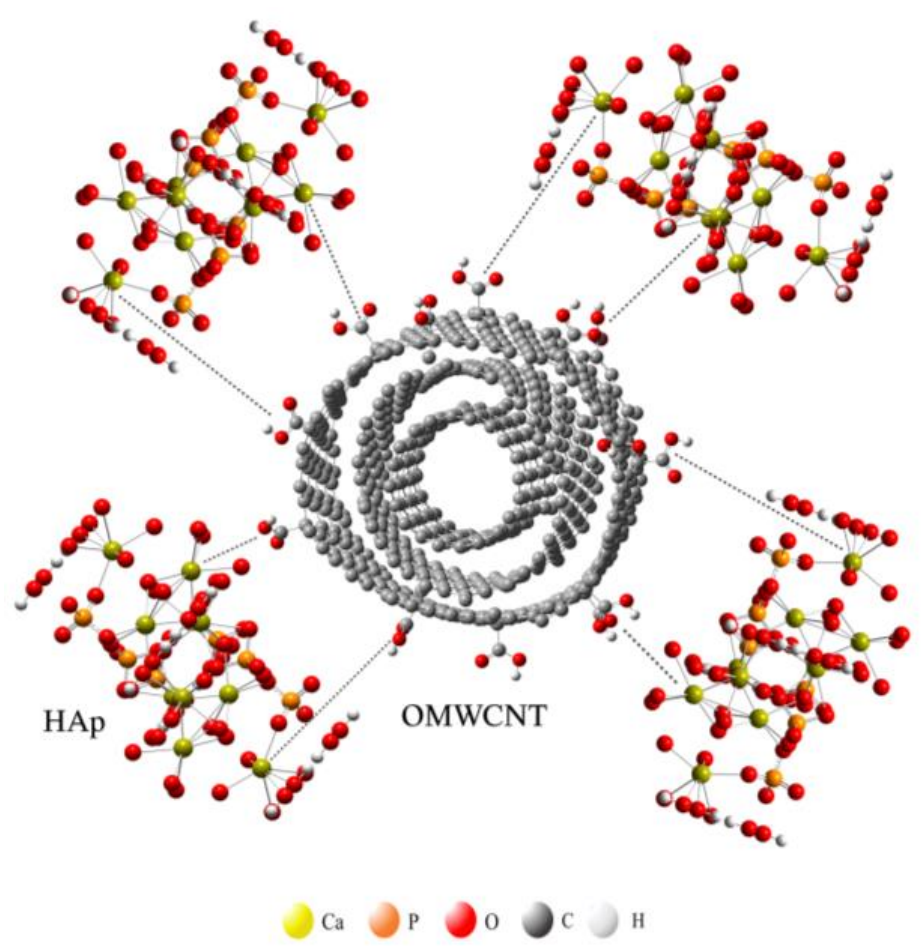

Figure 5. Interaction between HAp with OMWCNT to form the HAp/OMWCNT composite.

\subsection{Morphological Analysis}

The surface morphologies of MWCNT, OMWCNT, HAp, and HAp/OMWCNT are shown in Figure 6. Figure 6a presents the aligned, straight, and smooth surface of the MWCNT in comparison to the aligned, straight, and wavy surface of the OMWCNT. These results suggest that the functionalization of nanotubes with carboxyl groups can modify the morphology. Figure $6 \mathrm{c}$ shows the semi-spherical shape of HAp due to the fast nucleation during synthesis. Figure $6 \mathrm{~d}$ displays the HAp agglomerates formed by aggregation. The OMWCNTs are not visible because the HAp covers them. 


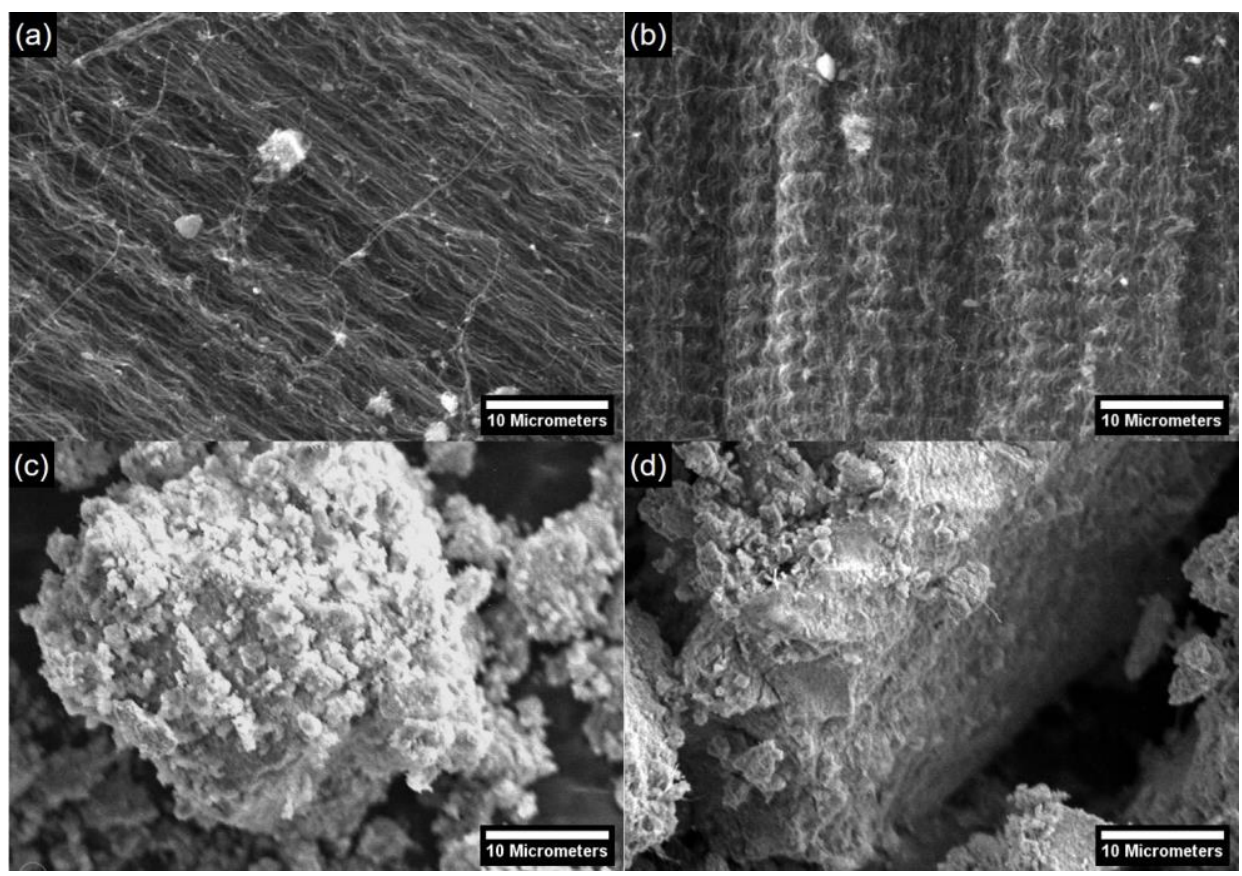

Figure 6. Scanning electron microscopy (SEM) images of MWCNT (a), OMWCNT (b), HAp (c), and HAp/OMWCNT composite (d).

\subsection{Compositional Analysis}

The compositional analysis by EDS showed that, as expected, all the samples contained $\mathrm{Ca}, \mathrm{P}$, and $\mathrm{O}$, and only the composites contained $\mathrm{C}$. This analysis also revealed that the HAp/OMWCNT sample had some impurities of $\mathrm{Al}$ and $\mathrm{Si}$ from cross-contamination, $\mathrm{Fe}$ traces from the MWCNT sample, and Br traces from the surfactant used in the synthesis; all are shown in Table 3. Then, a synchrotron XRF analysis detected several impurities of Ar, $\mathrm{Ni}, \mathrm{Zn}$, and Mo from cross-contamination in all the samples, because none of the reagents was composed of these elements. On the other hand, all the samples had $\mathrm{Br}$ residues from the surfactant, confirming that the HAp/OMWCNT sample also contained $\mathrm{Fe}$, as shown in Figure 7a-c. Finally, the $\mathrm{Al}$ and $\mathrm{Si}$ content was discarded from the HAp/OMWCNT sample (detected by EDS), because these elements were not detected by the synchrotron $\mathrm{XRF}$ analysis, which is a very sensitive and reliable technique. Besides that, the amounts of these elements were outside the scope of consideration.

The typical $\mathrm{Ca} / \mathrm{P}$ ratio in HAp is 1.67 [42], but when HAp is synthesized by the precipitation method, that expected ratio is lower [43], as shown in Table 3. The composites' $\mathrm{Ca} / \mathrm{P}$ ratio was higher than HAp, which is attributed to the substitution of the $\mathrm{PO}_{4}{ }^{3-}$ ion for the $\mathrm{CO}_{3}{ }^{2}$ ion or tetrahedral hydroxyl [42]. The HAp/OMWCNT sample with substitution type $\mathrm{B}$ (observed by FTIR) had a slightly higher amount of $\mathrm{CO}_{3}{ }^{2-}$ ions than the $\mathrm{PO}_{4}{ }^{3-}$ ions, thus resulting in an increased $\mathrm{Ca} / \mathrm{P}$ ratio in the composites.

Table 3. Compositional analysis by EDS and $\mathrm{Ca} / \mathrm{P}$ ratio of the three samples.

\begin{tabular}{ccccccccccc}
\hline & \multicolumn{1}{c}{ EDS (at. \%) } & Ca/P \\
\cline { 2 - 10 } & \multicolumn{1}{c}{ Element } \\
\hline Sample & Ca & $\mathbf{P}$ & $\mathbf{O}$ & $\mathbf{C}$ & $\mathbf{A l}$ & $\mathbf{S i}$ & $\mathbf{F e}$ & $\mathbf{B r}$ \\
\hline HAp & 20.83 & 13.24 & 65.93 & - & - & - & - & - & 1.57 \\
\hline HAp/OMWCNT & 12.78 & 6.46 & 35.29 & 45.35 & 0.76 & Traces & Traces & Traces & 1.98 \\
\hline HAp/MWCNT & 12.61 & 7.60 & 35.62 & 44.17 & - & - & - & - & 1.66 \\
\hline
\end{tabular}



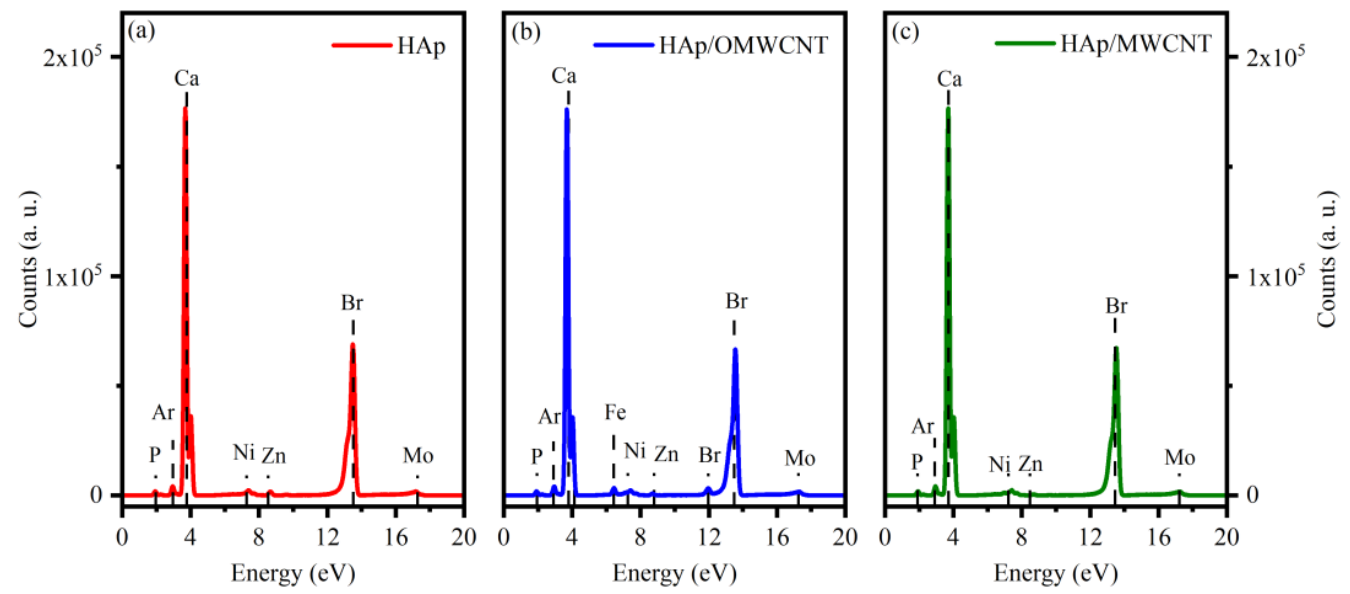

Figure 7. XRF spectra of the HAp (a), HAp/OMWCNT (b), and HAp/MWCNT (c) samples.

\subsection{Photoluminescence Spectroscopy}

Figure $8 \mathrm{a}-\mathrm{c}$ presents the photoluminescence spectra of the three samples and their corresponding deconvolution that shows each contribution in the luminescent process. Arabic numerals were used to label the HAp contribution bands, whereas those bands that belong to the MWCNT contribution were labeled with uppercase Roman numerals. The curves were deconvoluted using the Gaussian function in OriginPro 2019b software. The HAp and HAp/OMWCNT samples were adjusted to eight bands, while the HAp/MWCNT sample was adjusted to nine bands. Table 4 presents the exact position of each curve and the assignment to each contribution to explain their behavior.

Figure 8a displays the HAp spectra with a strong emission at $410 \mathrm{~nm}$ (blue), which is attributed to a significant amount of vacancy defects in the lattice due to the synthesis process, as reported by Zhang et al., where HAp did not reveal luminescence by itself [44]. These defects may be related to oxygen vacancies from the $\mathrm{PO}_{4}{ }^{3-}$ and $\mathrm{OH}^{-}$ions [45-48]. The FTIR spectra confirmed oxygen vacancies and loss of a complete $\mathrm{OH}^{-}$ion because the bands were weak. No contribution of HAp impurities to photoluminescent properties was observed, according to the works mentioned above.

In contrast, the HAp/OMWCNT composite spectrum indicated the effect of excitons from the OMWCNT sample, which was evidence of the peak shift to higher wavelengths, further distorting the peak symmetry [49]. Figure 8 shows that the HAp and HAp/MWCNT samples had a maximum photoluminescence emission at the $411 \mathrm{~nm}$ wavelength, while the HAp/OMWCNT sample had it at the $496 \mathrm{~nm}$ wavelength. These wavelength shifts in the spectrum occurred due to the presence of the functionalized MWCNTs, as reported by Sun et al., who found a maximum photoluminescence emission at $610 \mathrm{~nm}$; thus, it is evident that the OMWCNT sample contributed to those higher wavelength shifts [50]. When the HAp and OMWCNT samples combined their properties during synthesis at $250{ }^{\circ} \mathrm{C}$, there was no need to used high temperatures to obtain a composite material that reached the redshift in the photoluminescence emission [41].

In the figure above, the HAp/MWCNT sample has a band profile similar to that of HAp but a lower photoluminescence intensity due to the lattice arrangement, as previously observed in the XRD section. 

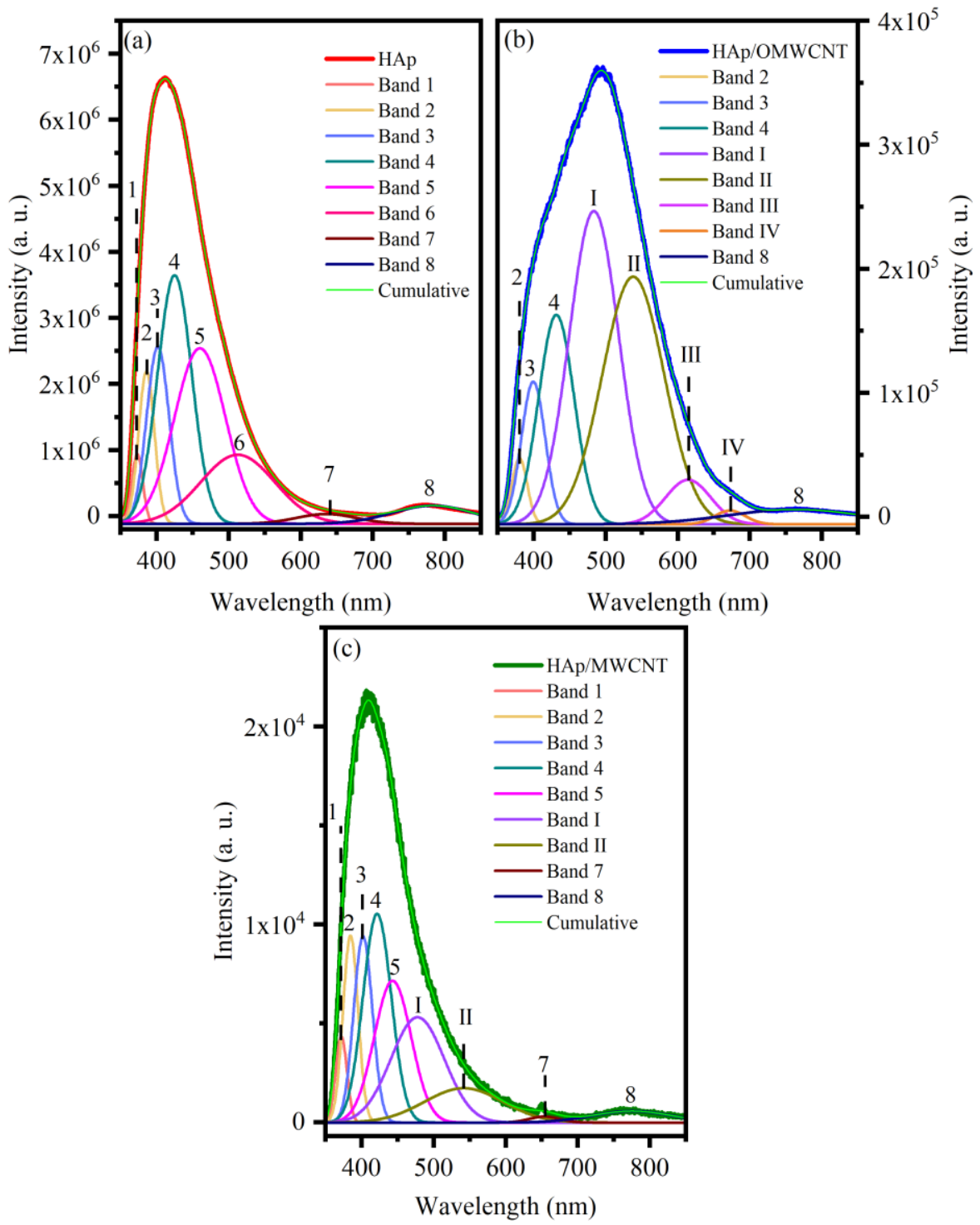

Figure 8. Photoluminescence spectra deconvolution of the HAp (a), HAp/OMWCNT (b), and HAp/MWCNT (c) samples.

Table 4. Photoluminescence emission bands of the HAp and composite samples.

\begin{tabular}{|c|c|c|c|c|c|}
\hline Sample & Band & Wavelength (nm) & Energy (eV) & Associated With & Ref. \\
\hline \multirow{8}{*}{ HAp } & 1 & 373.41 & 3.32 & Oxygen vacancies from $\mathrm{PO}_{4}{ }^{3-}$ ion & {$[47]$} \\
\hline & 2 & 386.17 & 3.21 & $\begin{array}{l}\text { Oxygen vacancies from } \mathrm{PO}_{4}{ }^{3-} \text { ion, bulk, } \\
\text { and surface defects }\end{array}$ & {$[45,46,48]$} \\
\hline & 3 & 401.93 & 3.08 & $\mathrm{OH}^{-}$ion vacancies & [47] \\
\hline & 4 & 425.29 & 2.91 & Oxygen vacancies from $\mathrm{OH}^{-}$ion & [47] \\
\hline & 5 & 460.44 & 2.69 & $\mathrm{OH}^{-}$and $\mathrm{H}^{+}$ion vacancies & [47] \\
\hline & 6 & 512.93 & 2.41 & $\mathrm{Ca}^{2+}$ vacancies & [47] \\
\hline & 7 & 635.81 & 1.95 & $\mathrm{OH}^{-}$ion vacancies & {$[45,47]$} \\
\hline & 8 & 783.34 & 1.58 & $\begin{array}{l}\text { Oxygen vacancies from } \mathrm{PO}_{4}{ }^{3-} \text { ion and } \\
\mathrm{OH}^{-} \text {ion vacancies }\end{array}$ & [45] \\
\hline
\end{tabular}


Table 4. Cont.

\begin{tabular}{|c|c|c|c|c|c|}
\hline Sample & Band & Wavelength (nm) & Energy (eV) & Associated With & Ref. \\
\hline \multirow{8}{*}{ HAp/OMWCNT } & 2 & 381 & 3.25 & $\begin{array}{l}\text { Oxygen vacancies from } \mathrm{PO}_{4}^{3-} \text { ion, bulk, } \\
\text { and surface defects }\end{array}$ & {$[45,46,48]$} \\
\hline & 3 & 399 & 3.10 & $\mathrm{OH}^{-}$ion vacancies & [47] \\
\hline & 4 & 431 & 2.88 & Oxygen vacancies from $\mathrm{OH}^{-}$ion & [47] \\
\hline & I & 483 & 2.57 & Exciton from carbon nanotubes & [49] \\
\hline & II & 538 & 2.30 & Exciton from carbon nanotubes & [49] \\
\hline & III & 615 & 2.02 & Exciton from carbon nanotubes & [50] \\
\hline & IV & 673 & 1.84 & $\begin{array}{l}\text { Exciton from carbon nanotubes, or } \mathrm{OH}^{-} \\
\text {ion vacancies }\end{array}$ & {$[45,47,49]$} \\
\hline & 8 & 767 & 1.61 & $\begin{array}{l}\text { Oxygen vacancies from } \mathrm{PO}_{4}{ }^{3-} \text { ion and } \\
\mathrm{OH}^{-} \text {ion vacancies }\end{array}$ & {$[45]$} \\
\hline \multirow{9}{*}{ HAp/MWCNT } & 1 & 372.13 & 3.33 & Oxygen vacancies from $\mathrm{PO}_{4}{ }^{3-}$ ion & [47] \\
\hline & 2 & 384.84 & 3.22 & $\begin{array}{l}\text { Oxygen vacancies from } \mathrm{PO}_{4}{ }^{3-} \text { ion, bulk, } \\
\text { and surface defects }\end{array}$ & {$[45,46,48]$} \\
\hline & 3 & 402.24 & 3.08 & $\mathrm{OH}^{-}$ion vacancies & [47] \\
\hline & 4 & 421.76 & 2.94 & Oxygen vacancies from $\mathrm{OH}^{-}$ion & [47] \\
\hline & 5 & 443.38 & 2.79 & $\mathrm{OH}^{-}$and $\mathrm{H}^{+}$ion vacancies & [47] \\
\hline & I & 477.94 & 2.59 & Exciton from carbon nanotubes & [49] \\
\hline & II & 542.15 & 2.28 & Exciton from carbon nanotubes & [49] \\
\hline & 7 & 654.11 & 1.89 & $\mathrm{OH}^{-}$ion vacancies & {$[45,47]$} \\
\hline & 8 & 775.37 & 1.59 & $\begin{array}{l}\text { Oxygen vacancies from } \mathrm{PO}_{4}{ }^{3-} \text { ion and } \\
\mathrm{OH}^{-} \text {ion vacancies }\end{array}$ & [45] \\
\hline
\end{tabular}

\section{Conclusions}

Luminescent HAp and composites were synthesized by the co-precipitation method followed by ultrasound bath and microwave radiation. The HAp sample had a strong blue emission because of oxygen defects in the lattice, whereas the HAp/MWCNT sample had a weak blue emission. The HAp/OMWCNT composite had a white emission due to the interaction between $\mathrm{Ca}^{2+}$ from HAp and carboxylic groups from OMWCNTs. In composite materials, OMWCNT contributed to the maximum photoluminescence emissions. The hexagonal phase in HAp and composites was obtained at $250{ }^{\circ} \mathrm{C}$ by the synthesis method used, in contrast to a higher temperature in previous reports. Here, we have reported a simple method to obtain HAp and composite materials without using rare earth elements in the synthesis.

The HAp/OMWCNT composite showed photoluminescent properties that make it a promising material for cell imaging and drug-release monitoring. This composite emits photoluminescence in the UV-visible range, where most confocal laser scanning microscopes are equipped. Drug release could be monitored by recovering luminescence from materials emitting in this wavelength range. Furthermore, the photoluminescence emission intensity of the composites obtained was comparable to materials used in bioimaging and biosensing. Similarly, relevant applications of HAp and HAp/OMWCNT composite may be developed in optoelectronics (light emitting diodes) owing to the great photoluminescent properties and salient characteristics of OMWCNTs.

Author Contributions: E.X.F.-R.: methodology, formal analysis, writing of original draft, and visualization. M.J.R.-Á.: conceptualization, methodology, validation, formal analysis, investigation, resources, writing of original draft, visualization, supervision, project administration, and funding 
acquisition. D.H.-C.: resources, writing, review, and editing. J.M.-J.: resources and funding acquisition. E.G.-D.: formal analysis, writing, review, and editing. S.A.S.-H.: formal analysis. All authors have read and agreed to the published version of the manuscript.

Funding: This work was financially supported by Consejo Nacional de Ciencia y Tecnología (CONACyT) [Grant Agreement No. 813372], Vicerrectoría de Investigación y Estudios de Posgrado (VIEP) [Project 100524279-VIEP2019], SASH thanks to the CONACyT program (Mexico) for post-doctoral grant (Project 136128), and IUPAP-IUCr LAAMP within the ICSU Grants Programme 2016-2019.

Institutional Review Board Statement: Not applicable.

Informed Consent Statement: Not applicable.

Data Availability Statement: The data presented in this study are openly available in Figueroa Rosales, Edna Xochitl (2021), "XRD \& XRF raw data”, Mendeley Data, V1, at [doi: 10.17632/nkpmdtdkfw.1].

Acknowledgments: The authors wish to thank Elettra Synchrotron Trieste for measuring the XRD in the beamline XRD1; Canadian Light Source for measuring the XRF in the beamline IDEAS; Centro Universitario de Vinculación y Transferencia de Tecnología at Benemérita Universidad Autónoma de Puebla for the compositional analysis; and Sc. D. Antonio Méndez Blas from Laboratorio Central del Instituto de Física at Benemérita Universidad Autónoma de Puebla for measuring the photoluminescence spectra. Special thanks to the LAAAMP (Lightsources for Africa, the Americas, Asia, Middle East, and the Pacific) Project for assistance in utilizing the light sources and for financial support.

Conflicts of Interest: The authors declare no conflict of interest.

\section{References}

1. Eliaz, N.; Metoki, N. Calcium Phosphate Bioceramics: A Review of Their History, Structure, Properties, Coating Technologies and Biomedical Applications. Materials 2017, 10, 334. [CrossRef] [PubMed]

2. Hench, L.L. Bioceramics: From Concept to Clinic. J. Am. Ceram. Soc. 1991, 74, 1487-1510. [CrossRef]

3. Mcconnell, D. Inorganic constituents in the shell of the living grachiopod Lingula. Geol. Soc. Am. Bull. 1963, 74, 363-364. [CrossRef]

4. Kramer, J.R. Sea Water: Saturation with Apatites and Carbonates. Science 1964, 146, 637-638. [CrossRef]

5. Fihri, A.; Len, C.; Varma, R.S.; Solhy, A. Hydroxyapatite: A review of syntheses, structure and applications in heterogeneous catalysis. Coord. Chem. Rev. 2017, 347, 48-76. [CrossRef]

6. Oulguidoum, A.; Bouiahya, K.; Bouyarmane, H.; Talbaoui, A.; Nunzi, J.-M.; Laghzizil, A. Mesoporous nanocrystalline sulfonated hydroxyapatites enhance heavy metal removal and antimicrobial activity. Sep. Purif. Technol. 2020, 255. [CrossRef]

7. Zhao, H.Y.; Zhou, H.M.; Zhang, J.X.; Zheng, W.; Zheng, Y.F. Carbon nanotube-hydroxyapatite nanocomposite: A novel platform for glucose $/ \mathrm{O}_{2}$ biofuel cell. Biosens. Bioelectron. 2009, 25, 463-468. [CrossRef]

8. Yang, P.; Yang, P.; Teng, X.; Lin, J.; Huang, L. A novel luminescent mesoporous silica/apatite composite for controlled drug release. J. Mater. Chem. 2011, 21, 5505-5510. [CrossRef]

9. Rončević, I.Š.; Buzuk, M.; Buljac, M.; Vladislavić, N. The Preparation, Morphological Characterization and Possible Electroanalytical Application of a Hydroxyapatite-Modified Glassy Carbon Electrode. Crystals 2021, 11, 1-14.

10. Wen, Y.; Li, J.; Lin, H.; Huang, H.; Song, K.; Duan, K.; Guo, T.; Weng, J. Improvement of Drug-Loading Properties of Hydroxyapatite Particles Using Triethylamine as a Capping Agent: A Novel Approach. Crystals 2021, 11, 703. [CrossRef]

11. Chen, M.; Yoshioka, T.; Ikoma, T. Photoluminescence and doping mechanism of theranostic $\mathrm{Eu}^{3+} / \mathrm{Fe}^{3+}$ dual-doped hydroxyapatite nanoparticles. Sci. Technol. Adv. Mater. 2014, 15, 9. [CrossRef] [PubMed]

12. Mahabole, M.; Bahir, M.; Khairnar, R. Mn blended hydroxyapatite nanoceramic: Bioactivity, Dielectric and Luminescence studies. J. Biomim. Biomater. Tissue Eng. 2013, 18, 43-59. [CrossRef]

13. Neacsu, I.A.; Stoica, A.E.; Vasile, B.S.; Andronescu, E. Luminescent Hydroxyapatite Doped with Rare Earth Elements for Biomedical Applications. Nanomaterials 2019, 9, 239. [CrossRef] [PubMed]

14. Paterlini, V.; Bettinelli, M.; Rizzi, R.; El Khouri, A.; Rossi, M.; Della Ventura, G.; Capitelli, F. Characterization and Luminescence of $\mathrm{Eu}^{3+}$ - and $\mathrm{Gd}^{3+}$-Doped Hydroxyapatite $\mathrm{Ca}_{10}\left(\mathrm{PO}_{4}\right)_{6}(\mathrm{OH})_{2}$. Crystals 2020, 10, 806. [CrossRef]

15. Goloshchapov, D.L.; Savchenko, D.V.; Kashkarov, V.M.; Khmelevskiy, N.O.; Aksenenko, A.Y.; Seredin, P.V. Study of the dependence of the structural defects and bulk inhomogeneities of nanocrystalline hydroxyapatite on the conditions of production using a biological source of calcium. J. Phys. Conf. Ser. 2019, 1400. [CrossRef]

16. Smith, A.M.; Duan, H.; Mohs, A.M.; Nie, S. Bioconjugated quantum dots for in vivo molecular and cellular imaging. Adv. Drug Deliv. Rev. 2008, 60, 1226-1240. [CrossRef]

17. Mao, L.-C.; Zhang, X.-Y.; Wei, Y. Recent Advances and Progress for the Fabrication and Surface Modification of AIE-active Organic-inorganic Luminescent Composites. Chin. J. Polym. Sci. 2019, 37, 340-351. [CrossRef]

18. Avouris, P.; Chen, J. Nanotube electronics and optoelectronics. Mater. Today 2006, 9, 46-54. [CrossRef] 
19. Wang, W.; Zhu, Y.; Watari, F.; Liao, S.; Yokoyama, A.; Omori, M.; Ai, H.; Cui, F. Carbon nanotubes/hydroxyapatite nanocomposites fabricated by spark plasma sintering for bonegraft applications. Appl. Surf. Sci. 2012, 262, 194-199. [CrossRef]

20. Constanda, S.; Stan, M.S.; Ciobanu, C.S.; Motelica-Heino, M.; Guégan, R.; Lafdi, K.; Dinischiotu, A.; Predoi, D. Carbon NanotubesHydroxyapatite Nanocomposites for an Improved Osteoblast Cell Response. J. Nanomater. 2016, 2016, 1-10. [CrossRef]

21. Iijima, S. Helical microtubules of graphitic carbon. Nature 1991, 354, 56-58. [CrossRef]

22. Dresselhaus, M.S.; Avouris, P. Introduction to Carbon Materials Research. In Carbon Nanotubes; Springer: Berlin/Heidelberg, Germany, 2007; Volume 9, pp. 1-9.

23. Riggs, J.E.; Guo, Z.; Carroll, D.L.; Sun, Y.-P. Strong Luminescence of Solubilized Carbon Nanotubes. J. Am. Chem. Soc. 2000, 122, 5879-5880. [CrossRef]

24. O'Connell, M.J.; Bachilo, S.M.; Huffman, C.B.; Moore, V.C.; Strano, M.S.; Haroz, E.H.; Rialon, K.L.; Boul, P.J.; Noon, W.H.; Kittrell, C.; et al. Band Gap Fluorescence from Individual Single-Walled Carbon Nanotubes. Science 2002, 297, 593-596. [CrossRef] [PubMed]

25. Velmurugan, S.; Palanisamy, S.; Yang, T.C.-K.; Gochoo, M.; Chen, S.W. Ultrasonic assisted functionalization of MWCNT and synergistic electrocatalytic effect of nano-hydroxyapatite incorporated MWCNT-chitosan scaffolds for sensing of nitrofurantoin. Ultrason. Sonochem. 2020, 62, 104863. [CrossRef] [PubMed]

26. Kumar, M.; Kumar, R.; Kumar, S. Synergistic effect of carbon nanotubes and nano-hydroxyapatite on mechanical properties of polyetheretherketone based hybrid nanocomposites. Polym. Polym. Compos. 2020,1-12. [CrossRef]

27. Arul Xavier Stango, S.; Vijayalakshmi, U. Synthesis and characterization of hydroxyapatite/carboxylic acid functionalized MWCNTS composites and its triple layer coatings for biomedical applications. Ceram. Int. 2019, 45, 69-81. [CrossRef]

28. Ma, B.; Zhang, S.; Liu, R.; Qiu, J.; Zhao, L.; Wang, S.; Li, J.; Sang, Y.; Jiang, H.; Liu, H. Prolonged fluorescence lifetime of carbon quantum dots by combining with hydroxyapatite nanorods for bio-applications. Nanoscale 2017, 9, 2162-2171. [CrossRef]

29. Lahiri, D.; Ghosh, S.; Agarwal, A. Carbon nanotube reinforced hydroxyapatite composite for orthopedic application: A review. Mater. Sci. Eng. C 2012, 32, 1727-1758. [CrossRef]

30. Barabás, R.; de Souza Ávila, E.; Ladeira, L.O.; Antônio, L.M.; Tötös, R.; Simedru, D.; Bizo, L.; Cadar, O. Graphene Oxides/Carbon Nanotubes-Hydroxyapatite Nanocomposites for Biomedical Applications. Arab. J. Sci. Eng. 2020, 45, 219-227. [CrossRef]

31. Nguyen, T.T.; Pham, N.T.; Dinh, T.T.M.; Vu, T.T.; Nguyen, H.S.; Tran, L.D. Electrodeposition of Hydroxyapatite-Multiwalled Carbon Nanotube Nanocomposite on Ti6Al4V. Adv. Polym. Technol. 2020, 2020, 1-10. [CrossRef]

32. Castle, A.B.; Gracia-Espino, E.; Nieto-Delgado, C.; Terrones, H.; Terrones, M.; Hussain, S. Hydroxyl-Functionalized and N-Doped Multiwalled Carbon Nanotubes Decorated with Silver Nanoparticles Preserve Cellular Function. ACS Nano 2011, 5, $2458-2466$. [CrossRef]

33. Gates-Rector, S.; Blanton, T. The Powder Diffraction File: A quality materials characterization database. Powder Diffr. 2019, 34, 352-360. [CrossRef]

34. Bergmann, J.; Friedel, P.; Kleeberg, R. Extended Software/Methods Development Issue. IUCr Newsl. 1998, 20, 5-8.

35. Doebelin, N.; Kleeberg, R. Profex: A graphical user interface for the Rietveld refinement program BGMN. J. Appl. Crystallogr. 2015, 48, 1573-1580. [CrossRef] [PubMed]

36. Ali, N.H.M.; Subuki, I.; Hussain Ismail, M. Synthesized Hydroxyapatite Powder from Clamshell via Chemical Precipitation Method. Adv. Mater. Res. 2014, 911, 72-76. [CrossRef]

37. Aquilano, D.; Bruno, M.; Rubbo, M.; Massaro, F.R.; Pastero, L. Low Symmetry Polymorph of Hydroxyapatite. Theoretical Equilibrium Morphology of the Monoclinic $\mathrm{Ca}_{5}(\mathrm{OH})\left(\mathrm{PO}_{4}\right)_{3}$. Cryst. Growth Des. 2014, 14, 2846-2852. [CrossRef]

38. Gopi, D.; Shinyjoy, E.; Sekar, M.; Surendiran, M.; Kavitha, L.; Sampath Kumar, T.S. Development of carbon nanotubes reinforced hydroxyapatite composite coatings on titanium by electrodeposition method. Corros. Sci. 2013, 73, 321-330. [CrossRef]

39. Markovic, M.; Fowler, B.O.; Tung, M.S. Preparation and comprehensive characterization of a calcium hydroxyapatite reference material. J. Res. Natl. Inst. Stand. Technol. 2004, 109, 553-568. [CrossRef] [PubMed]

40. Berzina-Cimdina, L.; Borodajenko, N. Research of calcium phosphates using Fourier Transform Infrarred Spectroscopy. In Infrared Spectroscopy-Materials Science, Engineering and Technology; Theophile, T., Ed.; InTech: London, UK, 2012; pp. 127-134. ISBN 9789535105374.

41. Machado, T.R.; Sczancoski, J.C.; Beltrán-Mir, H.; Nogueira, I.C.; Li, M.S.; Andrés, J.; Cordoncillo, E.; Longo, E. A novel approach to obtain highly intense self-activated photoluminescence emissions in hydroxyapatite nanoparticles. J. Solid State Chem. 2016, 249, 64-69. [CrossRef]

42. McConnell, D. Crystal chemistry of hydroxyapatite its relation to bone mineral. Arch. Oral Biol. 1965, 10, 421-431. [CrossRef]

43. LeGeros, R.Z.; LeGeros, J.P. Dense Hydroxyapatite. In An Introduction to Bioceramics; World Scientific: Singapore, 1993; pp. 139-180.

44. Zhang, C.; Yang, J.; Quan, Z.; Yang, P.; Li, C.; Hou, Z.; Lin, J. Hydroxyapatite Nano- and Microcrystals with Multiform Morphologies: Controllable Synthesis and Luminescence Properties. Cryst. Growth Des. 2009, 9, 2725-2733. [CrossRef]

45. Bystrov, V.S.; Piccirillo, C.; Tobaldi, D.M.; Castro, P.M.L.; Coutinho, J.; Kopyl, S.; Pullar, R.C. Oxygen vacancies, the optical band gap (Eg) and photocatalysis of hydroxyapatite: Comparing modelling with measured data. Appl. Catal. B Environ. 2016, 196, 100-107. [CrossRef] 
46. Machado, T.R.; Sczancoski, J.C.; Beltrán-Mir, H.; Li, M.S.; Andrés, J.; Cordoncillo, E.; Leite, E.; Longo, E. Structural properties and self-activated photoluminescence emissions in hydroxyapatite with distinct particle shapes. Ceram. Int. 2017, 44, $236-245$. [CrossRef]

47. Huerta, V.J.; Fernández, P.; Gómez, V.; Graeve, O.A.; Herrera, M. Defect-related luminescence properties of hydroxyapatite nanobelts. Appl. Mater. Today 2020, 21, 100822. [CrossRef]

48. Rosenman, G.; Aronov, D.; Oster, L.; Haddad, J.; Mezinskis, G.; Pavlovska, I.; Chaikina, M.; Karlov, A. Photoluminescence and surface photovoltage spectroscopy studies of hydroxyapatite nano-Bio-ceramics. J. Lumin. 2007, 122-123, 936-938. [CrossRef]

49. Koyama, T.; Miyata, Y.; Asaka, K.; Shinohara, H.; Saito, Y.; Nakamura, A. Ultrafast energy transfer of one-dimensional excitons between carbon nanotubes: A femtosecond time-resolved luminescence study. Phys. Chem. Chem. Phys. 2012, 14, 1070-1084. [CrossRef] [PubMed]

50. Sun, W.; Huang, Z.; Zhang, L.; Zhu, J. Luminescence from multi-walled carbon nanotubes and the Eu(III)/multi-walled carbon nanotube composite. Carbon N. Y. 2003, 41, 1685-1687. [CrossRef] 